\title{
The future of resuscitative endovascular balloon occlusion in combat operations
}

\author{
Shane A Smith, ${ }^{1,2}$ R Hilsden, ${ }^{1,2}$ A Beckett, ${ }^{3,4}$ V C McAlister ${ }^{1,2}$
}

\begin{abstract}
Damage control resuscitation and early thoracotomy have been used to increase survival after severe injury in combat. There has been a renewed interest in resuscitative endovascular balloon occlusion of the aorta (REBOA) in both civilian and military medical practices. REBOA may result in visceral and limb ischaemia that could be harmful if use of REBOA is premature or prolonged. The purpose of this paper is to align our experience of combat injuries with the known capability of REBOA to suggest an implementation strategy for the use of REBOA in combat care. It may replace the resuscitative effect of thoracotomy; can provide haemostasis of non-compressible torso injuries such as the junctional and pelvic haemorrhage caused by improvised explosive devices. However, prehospital use of REBOA must be in the context of an overall surgical plan and should be restricted to deployment in the distal aorta. Although REBOA is technically easier than a thoracotomy, it requires operator training and skill to add to the beneficial effect of damage control resuscitation and surgery.
\end{abstract}

\section{INTRODUCTION}

Resuscitative endovascular balloon occlusion of the aorta (REBOA) is an emerging technique used to support blood pressure and decrease haemorrhage in trauma, and the most enthusiastic supporters have suggested REBOA as a potential prehospital intervention to enable the exsanguinating patient with trauma to survive until surgical intervention ${ }^{1}$. London's Air Ambulance Service has begun using this technology in the prehospital environment. $^{2}$

Modern conflicts have seen a shift in the type of weapons used against coalition soldiers. In the recent Afghanistan war, fewer soldiers were injured with rifles than by improvised explosive devices (IED). ${ }^{3}$ IED victims present the

\footnotetext{
${ }^{1}$ General Surgery, Western University, London, Canada ${ }^{2}$ General Surgery, Royal Canadian Medical Service, London, Canada

${ }^{3}$ General Surgery, McGill University Health Centre, Montreal, Canada

${ }^{4}$ General Surgery, Royal Canadian Medical Service, Montreal, Canada
}

Correspondence to Shane A Smith, General Surgery, Western University, London, ON N6A 3K7, Canada; shaneasmith3@gmail.com challenge of non-compressible torso haemorrhage. ${ }^{4}$ With Tactical Combat Casualty Care (TCCC) and personal protective equipment, more soldiers are being treated for, and surviving, potentially preventable causes of death on the battlefield. ${ }^{5}$ However, until now, there has been very little a forward military physician can offer a patient with non-compressible torso haemorrhage other than rapid evacuation to a surgical facility. The use of REBOA may allow more soldiers to survive to receive surgical care.

\section{REBOA IN THE MILITARY}

The origins of REBOA are in military medicine. Lieutenant-Colonel Carl Hughes of the US Army Medical Corps used balloon aortic occlusion in two patients in the Korean Conflict, and although both died he speculated that this technique could save lives and he wished he had applied it sooner. ${ }^{6}$ Aortic balloon occlusion for haemorrhage control was first adopted in the civilian context for the management of abdominal aortic aneurysms ${ }^{7}$ and has been used as a technique for controlling exsanguination from postpartum haemorrhage and upper gastrointestinal bleeding. It is only in the past decade that REBOA for patients with trauma has transitioned from an experimental technique to a tool for clinical study and use. ${ }^{8}$

Interest in REBOA re-emerged within the military context during the Afghanistan and Iraq conflicts, and military surgeons have been actively involved in its research and development. ${ }^{8}$ The American military has published the Joint Trauma System Clinical Practice Guideline for REBOA, identifying its use as an alternative approach to thoracotomy in some cases and described a role for pre-emptive placement in high-risk unstable patients. ${ }^{9}$ This guideline is designed to be applied in a location with surgical capability, and a REBOA data tool is used to capture the technique's use for study. REBOA is less morbid than a resuscitative thoracotomy and may have a role in the hypotensive prearrest patient by increasing their blood pressure and decreasing haemorrhage before progression to arrest and the need for resuscitative thoracotomy. A recent systematic review showed that
REBOA increased systolic blood pressure by a mean of $53 \mathrm{~mm} \mathrm{Hg}$ (95\% CI 41 to $61 \mathrm{~mm} \mathrm{Hg}$ ), but it did not demonstrate a clear reduction in haemorrhage-related mortality. ${ }^{10}$ The studies comprising this review were case series, case reports and cohort studies; as registries accrue, prospective studies may illuminate additional circumstances showing an advantage of the REBOA technique in treating trauma patients with difficult to control haemorrhage.

Where REBOA portends great theoretical advantage is in the evacuation of combat casualties. Morrison et al's analysis of the UK joint trauma registry over a 10-year period identified 174 deaths that had indications for REBOA; 145 of these patients died before reaching hospital (83\%), with a mean time to death of $75 \mathrm{~min}$. The authors suggested that REBOA could act as en route haemorrhage control to get these casualties to a surgeon; as many as $18 \%$ of modern combat casualties may benefit from REBOA treatment. ${ }^{11}$ Current dogma encourages early compressible haemorrhage control and rapid evacuation. REBOA may be contrary to this effect if it results in delays in evacuation or it could be harmful if placed inappropriately. Before REBOA can be safely implemented in a forward environment, medical leadership must make decisions regarding what methods should be used to gain arterial access, the zone of REBOA deployment, plans for evacuating and receiving REBOA patients and what training would be required for medical officers using this therapy.

\section{ARTERIAL ACCESS}

Arterial access is the first step in deployment of REBOA. Vascular cut-down yields direct visualisation of the target vessel, facilitating reliable cannulation of the common femoral artery in a patient who is pulseless or profoundly hypotensive. However, it can be time consuming and requires surgical training. Landmark percutaneous access carries increased risk of venous cannulation, increased risk of vascular injury and has overall lower success rates. ${ }^{12}$ Additionally, the probability of successful placement is compromised in the patients who are extremely hypotensive or pulseless. ${ }^{10}$ Ultrasound-guided femoral artery access has the advantage of facilitating catheter placement in the patient who is hypotensive without requiring a cut-down. It may increase the speed of percutaneous access, and the ultrasound can also be used to 
confirm the positioning of the balloon. ${ }^{1}$ For the combat casualty in a non-surgical environment, ultrasound-guided percutaneous vascular access is the most attractive option. Such an approach alleviates the training requirement for performing a cut-down, may still be performed in the context of hypotension and the use of ultrasound is a skill which may already familiar to military physicians.

\section{ZONE OF DEPLOYMENT}

In 2011, Stannard et al described the modern technique for REBOA insertion via femoral artery cannulation and defined three zones of balloon deployment. ${ }^{13}$ Zone I is the thoracic aorta extending from the subclavian artery to the coeliac artery, zone II is the non-occlusion zone between the coeliac artery and renal arteries and zone III is from the lowest renal artery to the iliac bifurcation. Deployment of REBOA in zone I is analogous to the haemostatic control of a resuscitative thoracotomy with crossclamping of the thoracic aorta. REBOA in zone III provides occlusion to help control pelvic or junctional haemorrhage without causing visceral ischaemia.

The most common REBOA zone of deployment in the civilian setting is zone I $(78.6 \%),{ }^{14}$ with the major disadvantage of deployment at this zone being the associated spinal cord and visceral ischaemia. In the swine model, $30 \mathrm{~min}$ of occlusion is well tolerated but by $90 \mathrm{~min}$ there is evidence of liver necrosis and renal dysfunction. ${ }^{15}$ Zone III deployment does not offer control of intra-abdominal haemorrhage; however, it provides excellent control of pelvic and junctional bleeding without the risk of visceral ischaemia. ${ }^{13}$ Zone III REBOA will likely be less cumbersome in a more forward environment and does not run the risk of life-threatening visceral ischaemia in the context of delayed evacuation. While personal protective equipment provides some thoracoabdominal protection, the injury pattern of the antipersonnel IED is associated with significant pelvic injury that may be amenable to this technique. These characteristics make zone III the most practical for the initial use of prehospital combat physicians, but if a zone III REBOA is inflated, proximal injuries may continue to bleed as blood pressure increases. The mechanism of injury, as well as external signs of proximal injury, should be considered when deploying the REBOA as they may be indicative of a need to tailor resuscitation according to the response to REBOA placement. Zone I combat REBOA may be a future reality, but the evacuation of the patient would need to be immediate with a short travel time to the operating room. The medical officer inflating the balloon needs to be fully cognisant of the consequences of visceral ischaemia as it would indeed be a tragedy if a soldier died of visceral ischaemia who had otherwise survivable injuries.

\section{REBOA AND EVACUATION}

Exsanguination is the leading cause of death on the battlefield and thus haemorrhage control must be the top priority of the provider treating the injured soldier. ${ }^{4}$ REBOA has the potential to help combat casualties survive to surgery in situations where they would otherwise die without aortic occlusion ${ }^{11}$; however, delaying transport of a combat casualty while attempting to perform interventions could also be problematic and deadly. Figure 1 represents a potential algorithm if a combat REBOA programme were implemented. Although in the hands of experts, REBOA can be deployed in $6 \mathrm{~min}^{14}$ rapid evacuation to a surgical facility should not be delayed for REBOA insertion. Given that the mean time to death of patients that would have potentially benefited from REBOA was $75 \mathrm{~min},{ }^{11}$ a patient who could be imminently evacuated would likely derive greater benefit from rapid access to higher level surgical care than from delayed evacuation and REBOA placement (Table 1).

\section{TRAINING}

REBOA is a new technique to military medicine, with the majority of data on REBOA coming from trauma and vascular surgeons with considerable endovascular experience. ${ }^{14}$ In the Japanese system, emergency physicians can be credentialed after performing REBOA three times during residency training. ${ }^{16}$ A REBOA patient may have their device placed by an emergency medicine physician and definitive treatment provided by interventional radiology without direct involvement of a surgeon. ${ }^{17}$ Prospective data from the Japan Trauma Data Bank was used to match REBOA patients to propensity score-adjusted non-REBOA patients and they found that patients who received REBOA were three times more likely to die than patients with similar severity of injuries who did not receive REBOA. ${ }^{16}$ A 24-patient Japanese series demonstrated that REBOA increased mean systolic blood pressure, but they encountered complications such as the balloons not deflating, vascular injury while trying to obtain access and a $12.5 \%$ requirement for amputation,

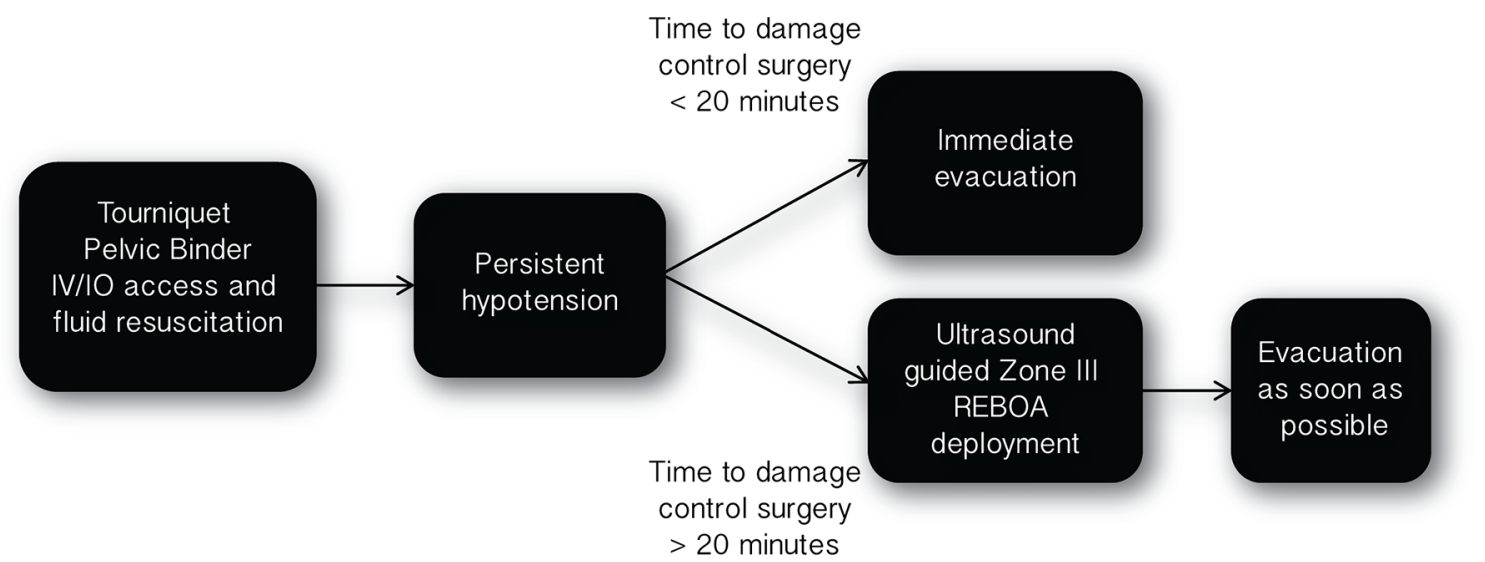

Figure 1 Potential algorithm for REBOA deployment for a combat casualty patient in a forward medical centre. Ongoing resuscitation, close patient monitoring and rapid evacuation are of paramount importance once aortic occlusion is achieved. If the mechanism of injury or external signs indicates a risk of proximal injury there may be a need to tailor resuscitation. IV, intavenous; IO, intraosseous; REBOA, resuscitative endovascular balloon occlusion of the aorta. 
Table 1 Considerations for use of REBOA at the echelons of care

\begin{tabular}{|c|c|c|c|}
\hline Role type & Description of role & Advantages of use & Disadvantages of use \\
\hline Role 4 & $\begin{array}{l}\text { Definitive medical care } \\
\text { Located outside of theatre }\end{array}$ & $\begin{array}{l}\text { Definite surgeon involvement } \\
\text { May avoid morbidity of a thoracotomy } \\
\text { Less risk of physician injury compared with } \\
\text { thoracotomy }\end{array}$ & $\begin{array}{l}\text { Could delay a necessary thoracotomy } \\
\text { Unlikely required at this level of care }\end{array}$ \\
\hline Role 3 & $\begin{array}{l}\text { Specialist surgical and medical capabilities } \\
\text { Intensive care capabilities } \\
\text { Holding capabilities }\end{array}$ & $\begin{array}{l}\text { Definite surgeon involvement } \\
\text { May avoid morbidity of a thoracotomy } \\
\text { Less risk of physician injury compared with } \\
\text { thoracotomy }\end{array}$ & - Could delay a necessary thoracotomy \\
\hline Role 2 & $\begin{array}{l}\text { Damage control resuscitation } \\
\text { Basic imaging and laboratory capabilities } \\
\text { Short-term holding of patients }\end{array}$ & $\begin{array}{l}\text { Likely surgeon involvement } \\
\text { May avoid morbidity of a thoracotomy } \\
\text { Less risk of physician injury compared with } \\
\text { thoracotomy } \\
\text { Military experience with REBOA in this environment }\end{array}$ & - Could delay a necessary thoracotomy \\
\hline Role 1 & $\begin{array}{l}\text { Primary care } \\
\text { Emergency resuscitation } \\
\text { Preparation for evacuation }\end{array}$ & $\begin{array}{l}\text { Performed by a physician } \\
\text { After initial damage control resuscitation } \\
\text { Opportunity for prophylactic placement } \\
\text { May allow more patients to survive to surgical care }\end{array}$ & $\begin{array}{l}\text { Patients not evaluated by a surgeon } \\
\text { May delay transport } \\
\text { May be used unnecessarily } \\
\text { Danger of prolonged ischaemia if evacuation } \\
\text { delayed }\end{array}$ \\
\hline Role 0 & - Point of injury care & $\begin{array}{l}\text { Earliest possible non-compressible haemorrhagic } \\
\text { control } \\
\text { Opportunity for prophylactic placement } \\
\text { May allow more patients to survive to surgical care }\end{array}$ & $\begin{array}{l}\text { Performed by non-physician } \\
\text { Before adequate resuscitation } \\
\text { May delay transport } \\
\text { May be used unnecessarily } \\
\text { Danger of prolonged ischaemia if evacuation } \\
\text { delayed } \\
\text { Difficult to deploy and use in tactical } \\
\text { environment }\end{array}$ \\
\hline
\end{tabular}

REBOA, resuscitative endovascular balloon occlusion of the aorta.

one of which arose from an iatrogenic vascular injury. ${ }^{18}$ The American experience as captured in the Aortic Occlusion for Resuscitation in Trauma and Acute Care Surgery (AORTA) registry has only reported three endovascular specific complications, including distal embolism and pseudo-aneurysm; no patients required amputations. ${ }^{14}$ Most contributors to the American AORTA registry are trauma and vascular surgeons who have taken, or are instructors on, REBOA training courses. ${ }^{14}$ Some have cautioned against the widespread adoption of REBOA at this time, fearing that use by less qualified practitioners may generate poorer outcomes before this technique has been adequately studied and its indications for use and required provider training have been defined. ${ }^{19}{ }^{20}$ It is important that medical officers placing REBOA in combat environments be adequately trained and their skillset maintained if the outcomes our soldiers deserve are to be achieved.

A prehospital military physician may be a trained surgeon, but more likely will be a general duty medical officer with experience in central line placement and ultrasound use, but not in endovascular techniques. Training curricula would need to be developed to ensure that they could safely place the device and know which patients may potentially benefit from the intervention. With the development of smaller calibre devices (7Fr) ${ }^{8}$ the possibility of training a medical officer to safely use REBOA is likely an achievable reality, but we must move towards this goal with prudence and careful planning supported by robust research. A strong training curriculum focused on both skillset acquisition and maintenance is crucial to a successful combat REBOA programme.

\section{FROM REBOA TO THE OPERATING ROOM}

In a multinational combat environment, it is normal to receive casualties from other nations. Even if a military did not adopt REBOA they may receive patients with a deployed REBOA device. For this reason, it behoves every military to be prepared to receive patients at their surgical facilities with REBOA. These patients should be taken directly to the operating room for evaluation and treatment, still being mindful to conduct primary and secondary trauma surveys. Communication is paramount since there is no visible aortic clamp; the surgical team must move with a sense of urgency given the ischaemic burden. If there are thoracic injuries a thoracotomy may need to be performed and if there is a zone I REBOA, the surgical team should palpate the balloon and either continue to use it for aortic occlusion or replace it with an aortic clamp. After thoracic injuries are addressed, a trauma laparotomy should be performed, aortic occlusion should be moved to infrarenal placement as haemostasis permits and clamps can then be placed on the individual iliac arteries with controlled reperfusion of one limb at a time. This will require communication and coordination with anaesthesia, as the limb may have been ischaemic for a prolonged period, potentially resulting in profound acidaemia and hyperkalaemia (Figure 2). The effect of reperfusion may be anticipated and appropriate prophylaxis (ie, calcium and sodium bicarbonate) given in a manner similar to organ reperfusion at transplantation. Receiving a patient with REBOA does not fundamentally change the surgical treatment of the combat casualty. It does however require excellent communication with anaesthesia identifying that there is aortic occlusion and movement of the balloon, or occlusion with appropriate clamping, must be conducted in a systematic and well-communicated fashion.

\section{THE FUTURE OF COMBAT REBOA}

Both military and civilian trauma surgical centres are using REBOA for the treatment of patients with haemorrhaging trauma ${ }^{914}$ within a framework of active 
clinical registries and ongoing research to clarify the use, safety and indications of this technique. REBOA should only be used in well-trained hands in an environment with ready surgical capabilities as the moment the balloon is inflated the patient must move towards definitive care, but REBOA does have promise as a forward medical tool. In the future, a physician at a forward medical centre, with appropriate training and skill set maintenance, will be able to insert a balloon under ultrasound guidance to occlude the aorta of an unstable combat casualty to allow them to survive to surgery where they otherwise would have died. REBOA could be placed prophylactically and be inflated should the patient deteriorate. This technology could become the next major advancement in combat casualty care; however, it will require clear protocols for use based on military requirements and high-quality research.

Contributors The manuscript was drafted by SAS and $\mathrm{RH}$. All authors contributed to analysis of the literature and creation of algorithms.

\section{Competing interests None declared.}

Provenance and peer review Not commissioned; externally peer reviewed.

(C) Article author(s) (or their employer(s) unless otherwise stated in the text of the article) 2017. All

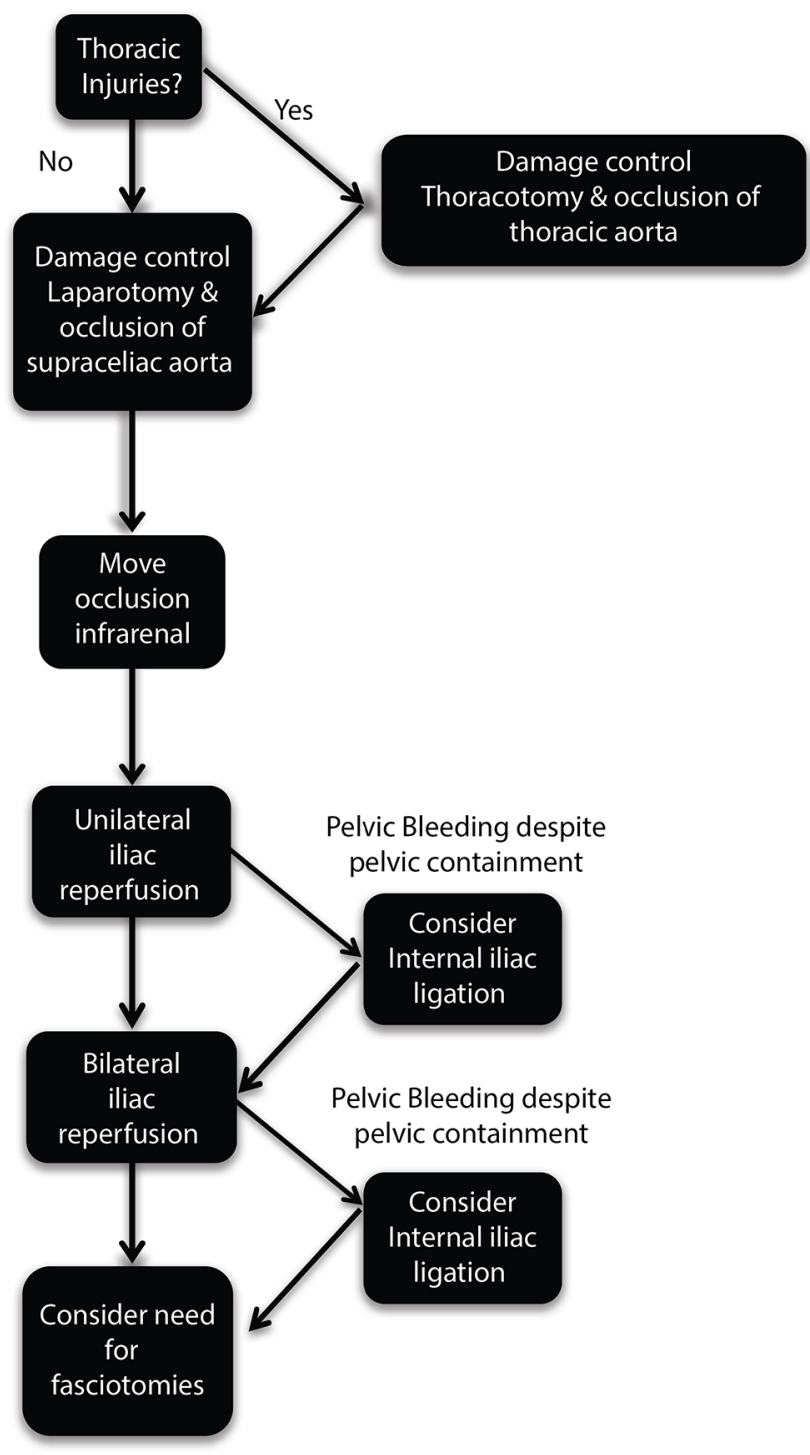

Figure 2 Potential algorithm for care of a REBOA patient at a military surgical facility. Patients should be brought to the operating room expeditiously. Thoracotomy should be conducted if there is evidence of thoracic trauma followed by laparotomy. Aortic occlusion should be sequentially moved distally as haemostasis allows. The iliac arteries should be perfused sequentially in coordination with anaesthesia and unilateral or bilateral internal iliac ligation can be considered if haemostasis is difficulty to obtain. Liberal use of extremity fasciotomies should be considered. REBOA, resuscitative endovascular balloon occlusion of the aorta.

rights reserved. No commercial use is permitted unless otherwise expressly granted.

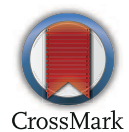

To cite Smith SA, Hilsden R, Beckett $A$, et al. J R Army Med Corps 2017;163:296-300.

Received 20 February 2017

Revised 10 April 2017

Accepted 13 April 2017

Published Online First 9 August 2017

J R Army Med Corps 2017;163:296-300.

doi:10.1136/jramc-2017-000788

\section{REFERENCES}

1 Chaudery M, Clark J, Morrison JJ, et al. Can contrastenhanced ultrasonography improve Zone III REBOA placement for prehospital care? I Trauma Acute Care Surg 2016;80:89-94.

2 Mundasad S. Balloon surgery stops fatal bleeding at roadside. 2014. http://www.bbc.com/news/health27868418. (accessed 20 Jan 2017).

3 Beckett A, Pelletier P, Mamczak C, et al. Multidisciplinary trauma team care in Kandahar Afghanistan: current injury patterns and care practices. Injury 2012;43:2072-7.

4 Morrison JJ, Stannard A, Rasmussen TE, et al. Injury pattern and mortality of noncompressible torso hemorrhage in UK combat casualties. J Trauma Acute Care Surg 2013;75:\$263-8.

5 Savage E, Forestier C, Withers N, et al. Tactical combat casualty care in the Canadian forces: lessons learned from the Afghan war. Can J Surg 2011;54:S118-23.

6 Hughes CW. Use of an intra-aortic balloon catheter tamponade for controlling intra-abdominal hemorrhage in man. Surgery 1954;36:65-8.

7 Robicsek F, Daugherty HK, Mullen DC. The elective use of balloon obstruction in aortic surgery. Surgery 1970:68:774-7.

8 Belenkiy SM, Batchinsky Al, Rasmussen TE, et al. Resuscitative endovascular balloon occlusion of the aorta for hemorrhage control: past, present, and future. J Trauma Acute Care Surg 2015;79:5236-42.

9 Joint Theater Trauma System Clinical Practice Guideline - Resuscitative Endovasctular balloon occlusion of the aorta (REBOA) for Hemorrhagic shock. 2014. http://www.usaisr.amedd.army.mil/clinical_practice_ guidelines.html. (accessed 10 Aug 2016).

10 Morrison JJ, Morrison JJ, Galgon RE, et al. A systematic review of the use of resuscitative endovascular balloon occlusion of the aorta in the management of hemorrhagic shock. J Trauma Acute Care Surg 2016;80:324-34.

11 Morrison JJ, Ross JD, Rasmussen TE, et al. Resuscitative endovascular balloon occlusion of the aorta: a gap analysis of severely injured UK combat casualties. Shock 2014;41:388-93.

12 Keller BA, Salcedo ES, Williams TK, et al. Design of a cost-effective, hemodynamically adjustable model for resuscitative endovascular balloon occlusion of the aorta (REBOA) simulation. J Trauma Acute Care Surg 2016;81:606-11.

13 Stannard A, Eliason JL, Rasmussen TE. Resuscitative Endovascular Balloon Occlusion of the Aorta (REBOA) as an adjunct for hemorrhagic shock. J Trauma 2011:71:1869-72.

14 DuBose JJ, Scalea TM, Brenner M, et al. The AAST prospective Aortic Occlusion for Resuscitation in Trauma and Acute Care Surgery (AORTA) registry: data on contemporary utilization and outcomes of aortic occlusion and resuscitative balloon occlusion of the aorta (REBOA). I Trauma Acute Care Surg 2016:81:409-19. 
15 Markov NP, Percival TJ, Morrison JJ, et al. Physiologic tolerance of descending thoracic aortic balloon occlusion in a swine model of hemorrhagic shock. Surgery 2013;153:848-56.

16 Norii T, Crandall C, Terasaka Y. Survival of severe blunt trauma patients treated with resuscitative endovascular balloon occlusion of the aorta compared with propensity score-adjusted untreated patients. J Trauma Acute Care Surg 2015;78:721-8.
17 Ogura T, Lefor AT, Nakano M, et al. Nonoperative management of hemodynamically unstable abdominal trauma patients with angioembolization and resuscitative endovascular balloon occlusion of the aorta. J Trauma Acute Care Surg 2015;78:132-5.

18 Saito N, Matsumoto H, Yagi T, et al. Evaluation of the safety and feasibility of resuscitative endovascular balloon occlusion of the aorta. I Trauma Acute Care Surg 2015;78:897-904.
19 Brenner M. REBOA and catheter-based technology in trauma. J Trauma Acute Care Surg 2015;79:174-5

20 Mattox KL. \#traumacon2016. KMattox presented support, but scathing cautions for using REBOA.Set rigid use \& evaluation \& time standards. [Twitter]. 2016. https://twitter. com/kmattox1/status/754110498530955264. (accessed 21 Jan 2017). 